\title{
Defect formation during dissimilar aluminium friction stir welded T-joints
}

\author{
Mubeen Ali ${ }^{1}$, Saquib Anjum ${ }^{1}$, Arshad Noor Siddiquee ${ }^{1, *}$, Zahid A. Khan ${ }^{1}$, Xizhang Chen ${ }^{2}$, Sergey Konovalov ${ }^{3}$, \\ Aisha Anjum ${ }^{1}$, Shafquat Shakeel ${ }^{1}$, and Hashmatullah Ibrahimi ${ }^{1}$ \\ ${ }^{1}$ Department of Mechanical Engineering, Jamia Millia Islamia, New Delhi, India \\ 2 School of Mechanical and Electrical Engineering, Wenzhou University, Wenzhou, PR China \\ ${ }^{3}$ Department of Metals Technology and Aviation Materials, Samara National Research University, Samara Oblast, Russia
}

Received: 6 August 2019 / Accepted: 17 January 2020

\begin{abstract}
AA8011 remains one of the largest used aluminium alloys due to excellent ductility, corrosion resistance and sufficient strength in H14 conditions. The 5754, due to high strength and corrosion resistance finds key applications in marine, process industry, automobile and nuclear applications. A T-joint combination of the two alloys (when stronger forming is stiffeners) results in significant weight savings. The T-joint between 8011 and 5754 (with the latter forming the stringer) is highly prone to defect formation due to the stronger material being placed away from the heat source. In this paper, friction stir welding of AA5754 and AA8011 aluminium alloys in T-lap configuration is performed. Effects of processing parameters namely tool transverse speed, rotational speed and shoulder diameter on the weld properties are studied with the help of micro-hardness, macrostructure and microstructure analysis. Analysis of defects such as tunnel and kissing bond, and mechanism of defect formation is also discussed. Tunnel defect is observed on advancing side in all the samples, which is attributed to high heat flux on advancing side, insufficient material flow in the vertical direction and asymmetric flow of plasticized material from advancing side to retreating side. The size of the defect is found to increase with increase in shoulder diameter keeping the rotational speed constant. Kissing bond defect was also observed in some samples owing to the presence of oxide layer between the joining surfaces.
\end{abstract}

Keywords: Friction stir welding / T-joint / dissimilar welding / tunnel defect / aluminium alloys

\section{Introduction}

The quest for weight reduction and high strength drive wide applications of Al-alloys in strategic sectors (in fabrication of stiffened panels by attaching stiffeners to skin sheets like in railway rolling stock, airframe structures, car bodies, structures in marine and nuclear power etc.). Typically, skin and stringer are mechanically joined in Tconfiguration. The prevalent joining methods based on mechanical processes are time, capital and skill intensive and also increase the weight of assembled joint. Furthermore, joining by conventional fusion-based welding processes softens the age-hardened alloys, introduces defects such as porosities, high residual stresses and distortion.

The advent of solid-state friction stir welding (FSW) process facilitated the joining of difficult to weld or even unweldable materials [1,2]. In FSW of T-joint [3,4], specially

\footnotetext{
* e-mail: arshadnsiddiqui@gmail.com
}

designed rotating tool with a pin at its end is inserted into the clamped plates and traversed along the joint. The simultaneous rotation and traverse of tool causes plastic flow of material from the advancing side (AS) to retreating side (RS) $[5,6]$. In AS, the directions of tool traverse and peripheral tool velocity vectors are the same; whereas in RS, these are opposite. Heat is generated due to the friction between tool and base material (BM), and due to plastic deformation of BM caused by stirring action of the pin. The heat flux causes local softening of the material without melting, thereby, preventing undesirable melting-related metallurgical defects.

The FSW is effective in fabricating age-hardened aluminium alloy panels [7-14]. Even an off-shoot of this welding technology: friction stir processing (FSP), is being applied for the manufacturing of aluminium metal matrix composites [15-18]. Recent studies by Donati et al., Buffa et al., Sun et al., Fratini et al., Feistauer et al., Durdevic et al. [19-24] have demonstrated that FSW has proved to be a promising technology for fabrication of T-joint and similar tailor-welded blanks (TWB) from high strength 
Table 1. Chemical composition of AA5754 (wt.\%).

\begin{tabular}{lllllllllll}
\hline Element & $\mathrm{Al}$ & $\mathrm{Si}$ & $\mathrm{Fe}$ & $\mathrm{Cu}$ & $\mathrm{Mn}$ & $\mathrm{Mg}$ & $\mathrm{Cr}$ & $\mathrm{Zn}$ & $\mathrm{Ti}$ & Others \\
\hline Wt.\% & Balance & 0.25 & 0.27 & 0.08 & 0.39 & 3.1 & 0.28 & 0.2 & 0.1 & $<0.15$ \\
\hline
\end{tabular}

Table 2. Chemical composition of AA8011 (wt.\%).

\begin{tabular}{lllllllllll}
\hline Element & $\mathrm{Al}$ & $\mathrm{Si}$ & $\mathrm{Fe}$ & $\mathrm{Mn}$ & $\mathrm{Ti}$ & $\mathrm{Cu}$ & $\mathrm{Pb}$ & $\mathrm{Sn}$ & $\mathrm{Ti}$ & $\mathrm{Zn}$ \\
\hline Wt.\% & Balance & 0.67 & 0.62 & 0.10 & 0.02 & 0.01 & 0.006 & 0.016 & 0.023 & $<0.010$ \\
\hline
\end{tabular}

age-hardened aluminium alloys. T-joint configurations are typically used in ships, decking and hull areas of high-speed crafts, and aircraft fuselage etc. Acerra et al. [25] performed FSW on AA2024-T4 and AA7075-T6 through a comprehensive experimental campaign on T-shaped parts and concluded that for carefully chosen tool geometry, a slight increase in the diameter of tool shoulder can increase the productivity rate. Feistauer et al. [23] studied the effect of reverse material flow on the microstructure of friction stir welded Al-Mg alloy T-joint, and observed that kissing bond (KB) defect drastically lowered the mechanical properties. The properties were significantly improved after second pass in the reverse direction. Ana Silva et al. [26] optimized the process parameter by Taguchi method and concluded that the rotational speed of FSW tool is the most important parameter which affected the mechanical properties of the joints. In comparison to butt joints, alleviation of defects in T-joint configuration poses different challenges. The defects such as tunnel, KB and zigzag lines are affected by tool geometry, geometry of mating surface (between rib or stringer and web or skin elements) and adequacy of clamping system. The size, orientation and distribution of various defects in T-joints have been investigated by some researchers [27-30]. Such defects commonly occur due to difficulty in ensuring effective material flow across the full stiffener width near the pin tip. Other issues like corner radius of rib clamp, rib-web interface, clamping of web and thinning of web-sheets etc. are common in T-joint. Apart from tunnelling and $\mathrm{KB}$, other problems include hooking defect, lack of full bonding at the root corners etc. that are difficult to eliminate in T-joint [30]. Literature reveals that several works on FSW of T-joints mostly report material flow characteristics, and numerical modelling which mainly remain limited to similar alloy combinations. The defects during T-joints have even prompted researchers to employ strategic filler material to avoid them [19]. Furthermore, most reported works on T-joint welding is performed on similar alloys with the exception of few [25], wherein the authors reported a case study of T-joint between AA2024 and AA7075. The joining of dissimilar material pair having widely different mechanical properties with stronger material placed as stringer is inherently challenging. Main challenge lies in the fact that the stringer located at the bottom receives lesser heat and it is difficult to consolidate.
Table 3. Mechanical properties of base material (BM).

\begin{tabular}{lll}
\hline Al Alloy & AA5754 & AA8011 \\
\hline Tensile strength (MPa) & 227.8 & 137.8 \\
Hardness (HV) & 68.4 & 46 \\
\hline
\end{tabular}

In this work, the effect of tool geometry (three different geometries) for dissimilar T-joint between AA5754 (stronger) and AA8011 (softer) has been investigated. The joining of 5754 and 8011 in this configuration may be a great enabler in weight reduction for strategic industrial sectors. A long T-joint may provide way for TWB fabrication leading to enhanced productivity, reduced cost and weight reduction. The defect analysis performed in the present work shall be useful to the researchers and professional working in the area to better understand the joint fabrication.

The present work is original and undertakes comprehensive work based on Taguchi's robust design (to ensure repeatability). The analysis of defect during T-joint with stronger material in the web and softer in the flange (which is commonly found in practical applications) is not adequately reported. In this work the size of defect (which is a common challenging problem to tackle in dissimilar tjoint formed between aluminium alloys of widely different mechanical properties) is measured and analysed in a comprehensive manner. The findings of this research may be highly useful in the effective welding and TWB fabrication.

\section{Experimental procedure}

AA5754-H24 (stringer) $200 \mathrm{~mm} \times 48.6 \mathrm{~mm} \times 3 \mathrm{~mm}$ in size, and AA8011-H14 (skin) $200 \mathrm{~mm} \times 70 \mathrm{~mm} \times 3 \mathrm{~mm}$ in sizes were welded. Chemical compositions of the two materials are given in Tables 1 and 2, respectively, and mechanical properties in Table 3. Prior to welding, the plates were washed, cleaned by organic solvent, rinsed and dried. Figure 1 shows the schematic view for transverse crosssection of the fabricated T-joint. The welding was performed by $\mathrm{H} 13$ die steel tools. The tool pin carried continuous taper in diameter (from 10 at the route to 


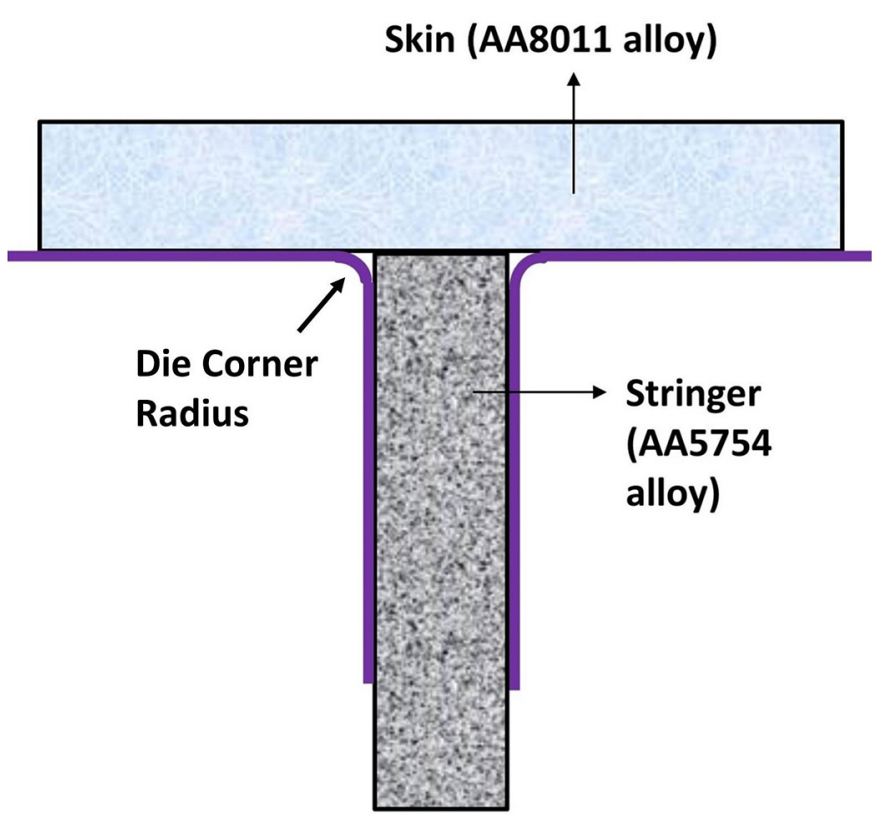

Fig. 1. Schematic view of transverse cross-section of fabricated T-joints.
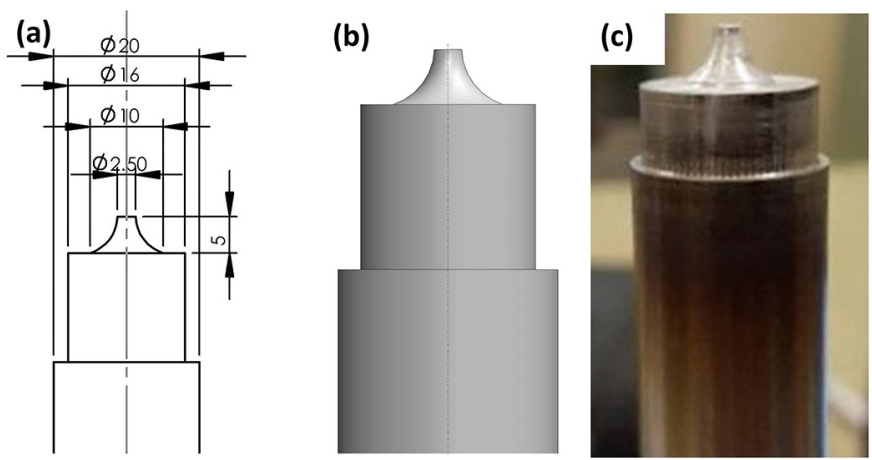

Fig. 2. FSW T-joint tool profile. (a) CAD drawing. (b) 3D model. (c) Actual tool.

$2.5 \mathrm{~mm}$ at the pin bottom) over $5 \mathrm{~mm}$ length as shown in Figure 2. The welds were performed on a sturdy Vertical Milling Machine (make: Bharat Fritz Werner, India; model VF3.5E) adapted to perform FSW.

Taguchi's L9 experimental design was employed to study the effects of three FSW parameters (listed in Tab. 4). The tool tilt angle at $2^{\circ}$, plunge depth $5.3 \mathrm{~mm}$ and clockwise tool rotation were maintained during welding. Specimens for optical microscopy (OM) and microhardness were machined from CNC Wire Electric Discharge Machine (Make: Steer corporation, India, Model DK7712). The OM samples were prepared using standard metallographic procedure of polishing and etching. The polished samples were chemically etched for $18 \mathrm{~s}$ using $2.5 \mathrm{ml} \mathrm{HF}, 42.5 \mathrm{ml} \mathrm{H}_{2} \mathrm{O}, 12 \mathrm{ml} \mathrm{Cr}_{2} \mathrm{O}_{3}, 30 \mathrm{ml} \mathrm{HCl}$ and $20 \mathrm{ml}$ $\mathrm{HNO}_{3}$. Micro-hardness across the transverse section of joints was measured by Vickers microhardness testing machine (Mitutoyo, Japan, Model MicroWizhard) at $1 \mathrm{~N}$ load and dwell time of $30 \mathrm{~s}$.
Table 4. FSW T-joint parameters.

\begin{tabular}{llll}
\hline $\begin{array}{l}\text { Sample } \\
\text { number }\end{array}$ & $\begin{array}{l}\text { Rotational } \\
\text { speed } \\
\text { (rpm) }\end{array}$ & $\begin{array}{l}\text { Welding } \\
\text { speed } \\
(\mathrm{mm} / \mathrm{min})\end{array}$ & $\begin{array}{l}\text { Shoulder } \\
\text { diameter } \\
(\mathrm{mm})\end{array}$ \\
\hline S1 & 710 & 40 & 14 \\
S2 & 710 & 50 & 16 \\
S3 & 710 & 63 & 18 \\
S4 & 900 & 40 & 16 \\
S5 & 900 & 50 & 18 \\
S6 & 900 & 63 & 14 \\
S7 & 1120 & 40 & 18 \\
S8 & 1120 & 50 & 16 \\
S9 & 1120 & 63 & 14 \\
\hline
\end{tabular}

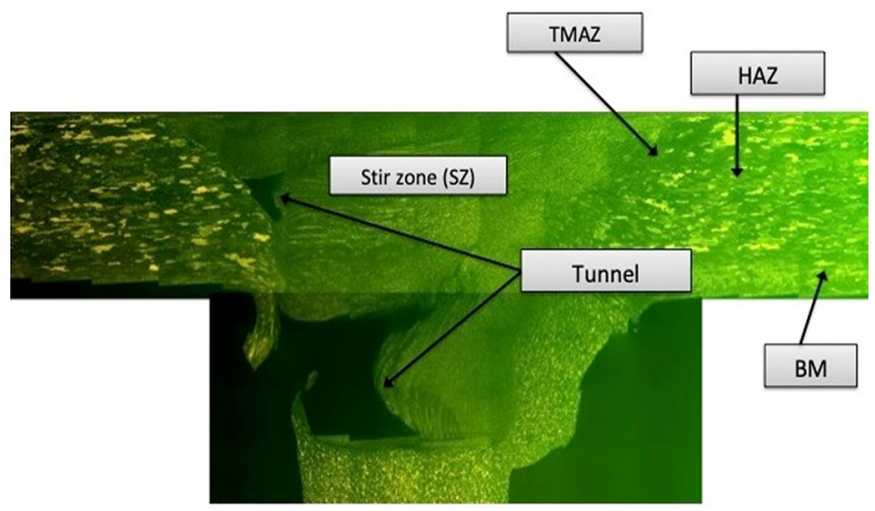

Fig. 3. Macrostructure of FS welded T-joint S4.

\section{Results}

Figure 3 represents the transverse-section macrostructure with identifiable T-joint FSW zones for experiment No. S4. Typically, similar macrostructural morphology was obtained in all the nine experiments. Different microstructural zones namely BM, stir zone (SZ), TMAZ (thermo mechanically affected zone) and heat affected zone (HAZ) are clearly observed as shown in Figure 4. The characteristically different structures in each zone relevantly contribute to the mechanical properties. SZ comprises of very fine grains as it is subjected to severe plastic deformation (SPD) and dynamic recrystallization (DRX) [31-34].

The hardness distribution on the cross section of Tjoints is shown in Figure 5. The micro-hardness measurements were traced to cover SZ, TMAZ and HAZ on AS and RS both over the transverse cross-section of the joints. The hardness plots for all the nine samples clearly indicate that all the nine parameter combinations affected the microhardness.

The microhardness profiles for samples welded at $710 \mathrm{rpm}$, transverse speed of 40,50 and $63 \mathrm{~mm} / \mathrm{min}$ and 

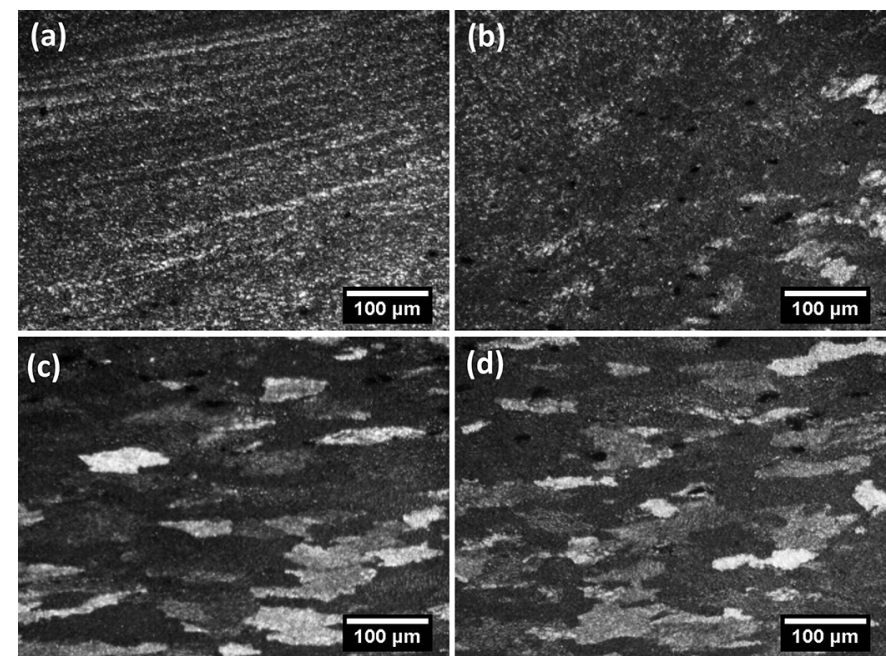

Fig. 4. Different micro-structural zones in weld S4 at 100X: (a) SZ, (b) TMAZ, (c) HAZ, (d) BM.

shoulder diameters 14, 16 and $18 \mathrm{~mm}$, respectively, are shown in Figure 5a. The micro-hardness value is highest at welding speed of $63 \mathrm{~mm} / \mathrm{min}$ and at shoulder diameter of $18 \mathrm{~mm}$. Figure $5 \mathrm{~b}$ presents the microhardness profile at $900 \mathrm{rpm}$ and transverse speed of 40,50 and $63 \mathrm{~mm} / \mathrm{min}$ and at shoulder diameters of 14,16 and $18 \mathrm{~mm}$ respectively. This indicates that hardness is maximum at $40 \mathrm{~mm} / \mathrm{min}$ and at shoulder diameter of $16 \mathrm{~mm}$. Finally, hardness variations for samples welded at $1120 \mathrm{rpm}$ and at welding speeds of 40, 50 and $63 \mathrm{~mm} / \mathrm{min}$ and shoulder diameter of 14,16 and $18 \mathrm{~mm}$ respectively are shown in Figure $5 \mathrm{c}$.

\section{Analysis of results and discussion}

\subsection{Micro-structure}

The frictional heat between the shoulder and top surface acts as a heat source and softens the material underneath the shoulder. The rotating shoulder and pin mix the softened material. There exists steep temperature gradient from the shoulder in the top (in 8011) to the bottom (in 5754) of the joint. Furthermore, the 5754 which forms the stringer (or web) is clamped between a pair of heavy fixture platens acting as heat sink. The 8011 which forms the skin (or flange), on the other hand, is in contact with heat source. The 5754 alloy is colder and is significantly stronger than 8011 (which is significantly hotter in comparison to 5754). The state of softening of materials being stirred is directly related to its strength and temperature prevailing in the individual materials. As the 8011 is in contact with heat source and its strength is very less (in comparison to 5754 ), it is significantly softer in comparison to 5754 .

The material at the web (i.e. 5754) is significantly stronger than 8011 and also the former is at significantly lesser temperature than the later. Accordingly, 8011 is considerably softer in comparison to 5754 , and consequently the former flows with considerable ease. Extrusion of material in the AS and its forging behind the tool in RS causes the vertical movement of the materials. The horizontal materials transport around the pin and adjacent to shoulder coupled with the vertical transport are responsible for stirring action. Stirring, thus mixes the materials from the bottom (which is colder and stiffer) to the top (which is hotter and softer) of the plates. Greater degree of stirring near the shoulder leads to greater refinement of the material in the $\mathrm{SZ}$ near to the shoulder through SPD assisted DRX, which results in the higher degree of grain refinement in the 8011 region of SZ.

During stirring, material from ahead of the tool gets transported $180^{\circ}$ around the tool and deposited by behind the tool [35]. Thus, the material in the AS ahead of the pin, undergoes greater displacement to get deposited behind the tool in the AS. The stirring and mixing of the two materials, which have significantly varied degrees of softening, is difficult. Because of characteristic material flow and widely varied softening state of the two BMs, the material deficiency on AS and excess material on RS (at the corner of stringer) can be observed in Figure 3. The SZTMAZ interface on AS contained defect in all joints. Furthermore, the SZ in stringer is narrow, which is attributed to less heat input at the pin bottom and low pin cross section in comparison to the shoulder. Therefore, the SZ, TMAZ and HAZ tend to be narrow in stringer as compared to skin. In TMAZ, the grains are distorted (elongated in the stirring direction) unlike equiaxed and ultrafine in SZ. Furthermore, the grains in HAZ are coarser than TMAZ due to the grain growth in HAZ which is subjected to thermal cycle only.

\subsection{Micro-hardness}

The highest micro-hardness (at $63 \mathrm{~mm} / \mathrm{min}$ traverse speed, $18 \mathrm{~mm}$ shoulder and $710 \mathrm{rpm}$ ) is attributed to the fact that the lowest tool rotation coupled with largest traverse speed created the lowest heat input condition. Furthermore, the largest shoulder diameter stirred the material with greater degree of plastic deformation at low heat input. The extensive SPD in-turn leads to greater DRX rate, and hence, higher hardness values.

Samples welded at $1120 \mathrm{rpm}$ form a sequence of decreasing heat input from S7 to S9. For all the welding and geometric parameters, the hardness is found to be more than the BM. The microhardness results for all samples also indicate that as the rotational speed increases the micro-hardness also increases [22]. This is attributed to the fact that an increase in rpm increases the degree of SPD, strain rate and also enhances the heat input. The SPD in hot state promotes DRX, ultrafine grain and high strain rate; all contribute to significant strength supported by multiple strengthening mechanisms and cumulative effect is manifested in enhanced micro-hardness.

\subsection{Defect characterization}

The parameters: rotational speed, welding speed and tool geometry play important role in defect formation as all have direct impact on heat generation and material flow during welding [36-41]. Tunnel defects and KB are the most prominent defects in FSW of T-joints [37]. In case of dissimilar T-joints the issue becomes more involved and 

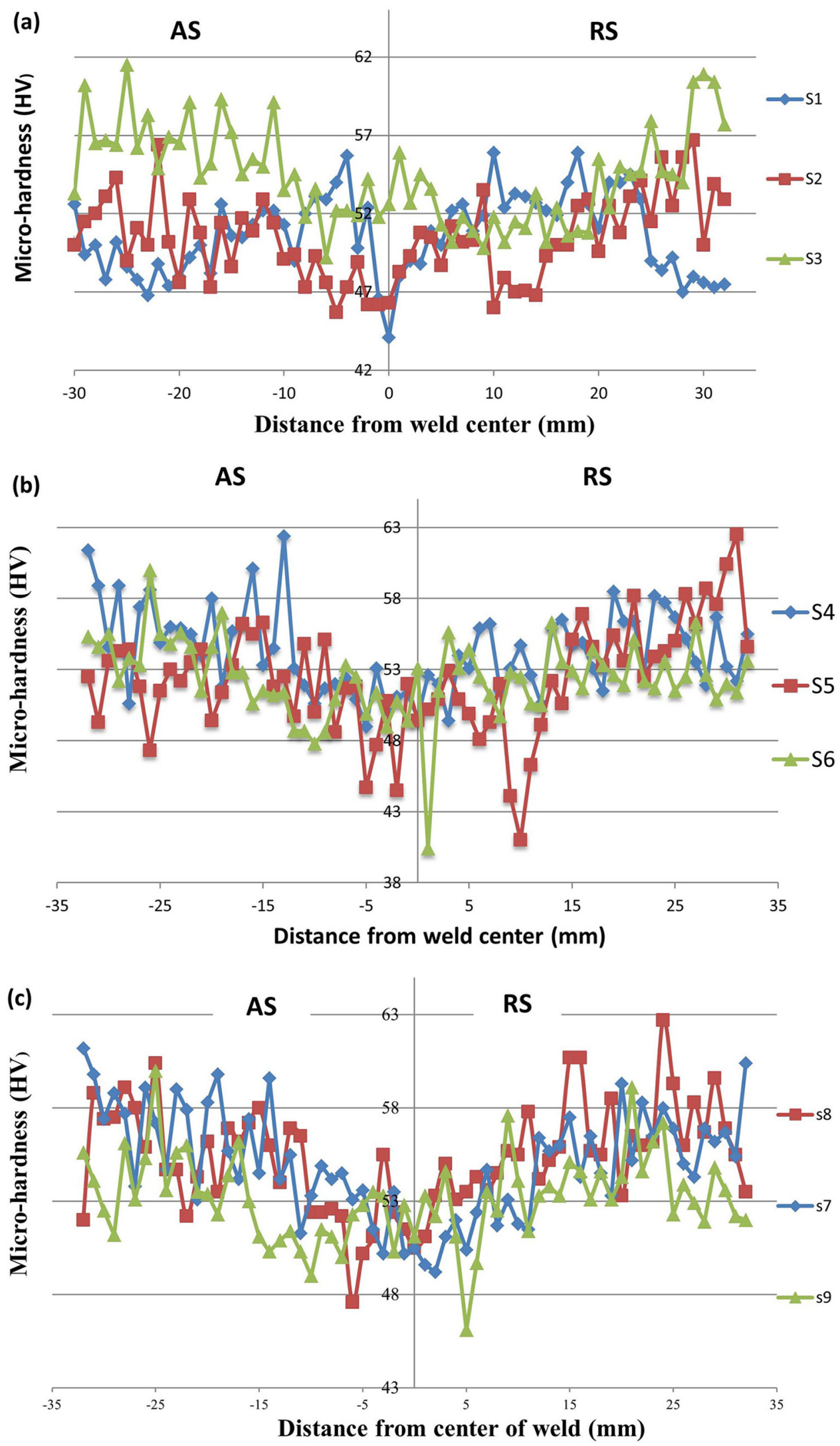

Fig. 5. Microhardness profile for (a) S1, S2 and S3 at rotational speed of $710 \mathrm{rpm}$, (b) S4, S5 and S6 at $900 \mathrm{rpm}$, and (c) S7, S8 and S9 at rotational speed of $1120 \mathrm{rpm}$. 
complex especially when the difference in mechanical properties of the two materials is widely different and the softer material forms an interface with the heat source. It is reported that during stirring of similar and homogeneous materials, the material lying in front of the tool in advancing and retreating sides, deposit on the same sides. Furthermore, material on both sides is deposited behind its original position relative to the welding direction at a displacement equal to one pin diameter [35]. Evidently, the material on the AS travels greater distance in comparison to that on RS. But in case of T-joints of dissimilar materials, wide difference in the softening state of the two materials causes great difference in the flow stress of the two materials.

\subsubsection{Tunnel defects}

All samples contained tunnel defects typical of what is depicted for S4 in Figure 3. Importantly, major tunnel exits at the root on AS; whereas, the minor tunnel is found at the middle of throat in the SZ-TMAZ interface on AS. This is attributed to the fact that there is no defect near the face of the weld (i.e. top surface) which is in contact with the heat source and most of the material is highly soft (less strong 8011 at high temperature). But as one goes down the weld throat, temperature reduces and the admixing of softer 8011 with stronger 5754 cause the average flow stress of consolidated materials to increase. The flow stress drastically increases as one goes from top (weld face) to the bottom (weld root) of the joint. Steep rise in flow stress and the fact that materials on AS traverse greater distance are responsible for the formation of small and large tunnels at the respective locations. To characterise and relate the tunnelling defect with the FSW parameters, entire area of the tunnel for every sample was measured using ImageJ software and the same is analysed. Smallest tunnelling defect was obtained in joint S1; whereas, severest defect was found in the joint S3. The size (area) of tunnelling defects for all the samples are given in Table 5.

Evidently, the tunnel defects in T-joints is mainly caused by deficient material deposition on the AS, which is attributed to two main reasons. Firstly, there is a steep rise in flow stress from top to bottom of the weld. This causes easier material flow near the top whereas the flow near the bottom remains heavily sluggish. Consequently, the material which is required to replenish the cavity left behind by the advancing tool is deficient resulting in tunnel. Secondly, as the flow stress drastically increases from top to bottom and material transport on the AS is considerably greater in comparison to that on RS. This results in the greater tunnel being observed on the AS at the weld root and a smaller tunnel at the mid depth of the weld-throat on TMAZ-SZ interface. It can be observed from the information given in Table 5 that tunnel area increases with increase in the shoulder diameter for a fixed value of rotational speed. It is pertinent to note that major contribution to heat input is tool rpm and as the shoulder increases it also causes greater volume of material to move which consequently results on greater size of the tunnel.
Table 5. Area of tunnelling defect for samples S1 to S9.

\begin{tabular}{ll}
\hline Samples & Area of tunnel $\left(\mathrm{mm}^{2}\right)$ \\
\hline S1 & 2.62 \\
S2 & 3.04 \\
S3 & 5.86 \\
S4 & 3.83 \\
S5 & 4.14 \\
S6 & 2.72 \\
S7 & 4.49 \\
S8 & 3.49 \\
S9 & 2.83 \\
\hline
\end{tabular}

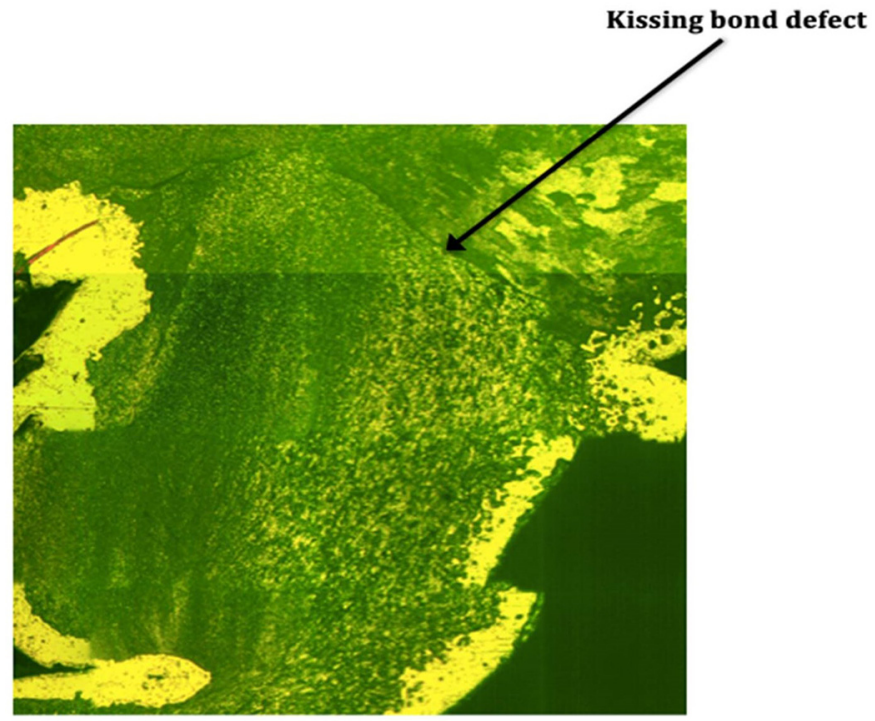

Fig. 6. Microstructure showing kissing bond in S6 weld.

\subsubsection{Kissing bond defect}

The KB defect is very common in FS welded T-joints. This defect is also observed in the current study. Figure 6 shows a typical KB defect present in weld No. S6. During welding, the stirring action results in rigorous material mixing and the faying surface between skin and stringer take a typical locus if not effectively stirred [42]. Oxide layer is present in the surfaces which form the interfaces between stringer and skin. If faying surfaces are not effectively whipped during stirring, the locus of faying surface with oxide layer present in-there manifests as KB [42]. The KB is attributed to inefficient mixing of base metals during FSW. In present case wide variation in the flow stress which is being very high near bottom is the main contributor to the KB.

\section{Conclusions}

In this study, an analysis of defect formation during friction stir welding of dissimilar T-joint between AA8011 and AA5754 alloys has been performed. Microhardness, 
macrostructure, microstructure and defect formation mechanisms were studied. The results obtained, if carefully used, can be utilized for the elimination of weld defects from Friction Stir Welded T-joints of aluminium alloys. Consequently, the successful application of Friction Stir Welded T-joints will result in higher strength to weight ratios of aerospace and automobile structures. On the basis of the obtained results and analyses thereof following conclusions are drawn:

- The 8011 being considerably softer in comparison to 5754 and it formed the interface with the heat source resulting in significant softening in upper part of the joint. Rigorous stirring due to shoulder effect resulted in the formation of ultra fine grains in the stir zone of 8011 region. The grain size reduction from the bottom (in the $5754)$ to the top (8011) was also observed which is attributed to the lower temperature, higher flow stress and less intense stirring in the 5754 .

- The tunnel in two different configurations; a major tunnel at the root on the AS and a minor tunnel at the middle of throat on the thermo-mechanically affected zone to stir zone interface were observed.

- The tunnel was mainly attributed to steep rise in flow stress from the top to the bottom of the weld. However, the variation in the flow stress coupled with the presence of oxide layers was the main reason for the kissing bond in the welded T-joints.

- For rotational speed of $710 \mathrm{rpm}$ (lowest), maximum hardness was found at welding speed of $63 \mathrm{~mm} / \mathrm{min}$ (highest) and shoulder diameter of $18 \mathrm{~mm}$ (greatest). This was attributed to the fact that the largest shoulder diameter transported large volume of material under the least heat input condition. Furthermore, at tool rotational speed of $1120 \mathrm{rpm}$, welding parameters with least heat input resulted in minimum hardness.

\section{References}

[1] R.S. Mishra, Z.Y. Ma, Friction stir welding and processing, Mater. Sci. Eng. R 50, 1-78 (2005)

[2] Y. Huang, M. Xiangchen, X. Yuming, W. Long, L. Zongliang, C. Jian, F. Jicai, Friction stir welding/processing of polymers and polymer matrix composites, Compos. Part A 105, 235-257 (2018)

[3] L. Fratini, G. Buffa, L. Filice, F. Gagliardi, FSW of AA6082T6 T-joints, Proc. Inst. Mech. Eng. B J. 220, 669-676 (2006)

[4] L. Fratini, F. Micari, A. Squillace, G. Giorleo, Experimental characterization of FSW T-joints of light alloys, Key Eng. Mater. 344, 751-758 (2007)

[5] M. Guerra, C. Schmidt, L.C. McClure, L.E. Murr, A.C. Nunes, Flow patterns during friction stir welding, Mater. Charact. 49, 95-101 (2003)

[6] C.G. Rhodes, M.W. Mahoney, W.H. Bingel, R.A. Spurling, C.C. Bampton, Effects of friction stir welding on microstructure of 7075 aluminum, Scr. Mater. 36, 69-75 (1997)
[7] A.C.F. Silva, D.F.O. Braga, M.A.V. de Figueiredo, P.M.G. P. Moreira, Friction stir welded T-joints optimization, Mater. Des. 55, 120-127 (2014)

[8] M.M.Z. Ahmed, S. Ataya, M.M. El-Sayed Seleman, H.R. Ammar, E. Ahmed, Friction stir welding of similar and dissimilar AA7075 and AA5083, J. Mater. Process. Technol. 242, 77-91 (2017)

[9] H.K. Pabandi, H.R. Jashnani, M. Paidar, Effect of precipitation hardening heat treatment on mechanical and microstructure features of dissimilar friction stir welded AA2024-T6 and AA6061-T6 alloys, J. Manuf. Process. 31, $214-220$ (2018)

[10] N. Martinez, N. Kumar, R.S. Mishra, K.J. Doherty, Microstructural variation due to heat gradient of a thick friction stir welded aluminum 7449 alloy, J. Alloys Compd 713, 51-63 (2017)

[11] S. Sinhmar, D.K. Dwivedi, Enhancement of mechanical properties and corrosion resistance of friction stir welded joint of AA2014 using water cooling, Mater. Sci. Eng. A 684, 413-422 (2017)

[12] D. Santos et al. Understanding precipitate evolution during friction stir welding of $\mathrm{Al}-\mathrm{Zn}-\mathrm{Mg}-\mathrm{Cu}$ alloy through in-situ measurement coupled with simulation. Acta Mater. 148, $163-172(2018)$

[13] H. Liu, Y. Hu, C. Dou, D.P. Sekulic, An effect of the rotation speed on microstructure and mechanical properties of the friction stir welded 2060-T8 Al-Li alloy, Mater. Character. 123, 9-19 (2017)

[14] H.R. Shercliff, M.J. Russell, A. Taylor, T.L. Dickerson, Microstructural modelling in friction stir welding of 2000 series aluminium alloys, Mech. Ind. 6, 25-35 (2005)

[15] N. Gangil, S. Maheshwari, A.N. Siddiquee, Influence of tool pin and shoulder geometries on microstructure of friction stir processed AA6063/SiC composites, Mech. Ind. 19, 6 (2018)

[16] X. Cao, Q. Shi, D. Liu, Z. Feng, Q. Liu, G. Chen, Fabrication of in situ carbon fiber/aluminum composites via friction stir processing: Evaluation of microstructural, mechanical and tribological behaviors, Composite B 139, 97-105 (2018)

[17] R. Senthilkumar, M. Prakash, N. Arun, A.A. Jeyakumar, The effect of the number of passes in friction stir processing of aluminum alloy (AA6082) and its failure analysis, Appl. Surf. Sci. 491, 420-431 (2019)

[18] A. Mostafa, M.H. Shojaeefard, P. Asadi, A. Khalkhali, Wear and mechanical properties of surface hybrid metal matrix composites on $\mathrm{Al}-\mathrm{Si}$ aluminum alloys fabricated by friction stir processing, Proc. Inst. Mech. Eng. L J. Mater 233, 790-799 (2019)

[19] L. Donati, L. Tomesani, A. Morri, Structural T-joint produced by means of friction stir welding (FSW) with filling material, Int. J. Mater. Forming 2, 295-298 (2009)

[20] G. Buffa, L. Fratini, V. Ruisi, Friction stir welding of tailored joints for industrial applications, Int. J. Mater. Forming 2, 311 (2009)

[21] T. Suna, M.J. Royb, D. Stronga, C. Simpsonc, P.J. Withersa, P.B. Prangnella, Weld zone and residual stress development in AA7050 stationary shoulder friction stir T-joint weld, J. Mater. Process. Technol. 263, 256-265 (2019)

[22] L. Fratini, G. Buffa, R. Shivpuri, Influence of material characteristics on plastomechanics of the FSW process for Tjoints, Mater. Des. 30, 2435-2445 (2009) 
[23] E.E. Feistauer, L.A. Bergmann, L.A. dos Santos, Effect of reverse material flow on the microstructure and performance of friction stir welded T-joints of an Al-Mg alloy, Mater. Sci. Eng. 731, 454 (2018)

[24] A. Đurđevića, A. Sedmakb, A. Zivkovićc, D. Đurđevića, M. Markovic, M. Milcis, Microhardness and microstructure of friction stir welded T- joint, Procedia Struct. Integr. 13, 424-429 (2018)

[25] F. Acerra, G. Buffa, L. Fratini, G. Torino, On the FSW of AA2024-T4 and AA7075-T6 T-joints: an industrial case study, Int. J. Adv. Manuf. Technol. 9-12, 1149 (2010)

[26] A.C.F. Silva, F.O. Braga, M.A.V. Figueiredo, P.M.G.P. Moreira, Friction stir welded T-joints optimization, Mater. Des. 55, 120-127 (2014)

[27] J.S. Jesus, J.M. Costa, A. Loureiro, J.M. Ferreira, Assessment of friction stir welding aluminium T-joints, J. Mater. Process. Technol. 255, 387-399 (2018)

[28] Y. Zhao, L. Zhou, Q. Wang, K. Yan, J. Zou, Defects and tensile properties of 6013 aluminum alloy T-joints by friction stir welding, Mater. Des. 57, 146-155 (2014)

[29] A. Astarita, A. Squillace, A. Scala, A. Prisco, On the critical technological issues of friction stir welding T-joints of dissimilar aluminum alloys, J. Mater. Eng. Perf. 21, 1763-1771 (2012)

[30] L. Cui, X. Yang, Y. Xie, X. Hou, Y. Song, Process parameter influence on defects and tensile properties of friction stir welded T-joints on AA6061-T4 sheets, Mater. Des. 51, 161-174 (2013)

[31] G. Zhou, X.Q. Yang, L. Cui, Z.H. Zhang, X.D. Xu, Study on the microstructures and tensile behaviors of friction stir welded T-joints for AA6061-T4 alloys, J. Mater. Eng. Perf. 21, 2131-2139 (2012)

[32] F.C. Liu, T.W. Nelson, In-situ grain structure and texture evolution during friction stir welding of austenite stainless steel, Mater. Des. 115, 467-478 (2017)
[33] W.F. Xu, Y.X. Luo, M.W. Fu, Microstructure evolution in the conventional single side and bobbin tool friction stir welding of thick rolled 7085-T7452 aluminum alloy, Mater. Charact. 138, 48-55 (2018)

[34] J. Han, J. Chen, L. Peng, S. Tan, Y. Wu, F. Zheng, H. Yi, Microstructure, texture and mechanical properties of friction stir processed Mg-14Gd alloys, Mater. Des. 130, 90-102 (2017)

[35] T.U. Seidel, A.P. Reynolds, Visualization of the material flow in AA2195 friction-stir welds using a Marker insert technique, Metal. Mater. Trans. 32, 2879-2888 (2001)

[36] C. Genevois, A. Deschamps, A. Denquin, B. Doisneaucottignies, Acta Mater. 53, 2447-2458 (2005)

[37] H. Xiaopeng, Y. Xinqi, C. Lei, Z. Guang, Influneces of joint geometry on defects and mechanical properties of friction stir welded AA6061-T4 T-joints, Mater. Des. 53, 106-117 (2014)

[38] M. Pourali, A. Abdollah-Zadeh, T. Saeid, F. Kargar, Influence of welding parameters on intermetallic compounds formation in dissimilar steel/aluminum friction stir welds, J. Alloys Compd. 715, 1-8 (2017)

[39] F. Heirani, A. Abbasi, M. Ardestani, Effects of processing parameters on microstructure and mechanical behaviors of underwater friction stir welding of Al5083 alloy, J. Manuf. Process. 25, 77-84 (2017)

[40] S. Shanavas, J.E. Raja Dhas, Parametric optimization of friction stir welding parameters of marine grade aluminium alloy using response surface methodology, Trans. Nonferrous Metals Soc. China 27, 2334-2344 (2017)

[41] F. Kordestani, F.A. Ghasemi, N.B. Mostafa Arab, An investigation of FSW process parameters effects on mechanical properties of PP composites, Mech. Ind. 17, 611 (2016)

[42] N.Z. Khan, A.N. Siddiquee, Z.A. Khan, S.K. Shihab, Investigation on tunneling and kissing bond defects in FSW joints for dissimilar aluminum alloys, J. Alloys Compds. 648, 360-367 (2017)

Cite this article as: M. Ali, S. Anjum, A.N. Siddiquee, Z.A. Khan, X. Chen, S. Konovalov, A. Anjum, S. Shakeel, H. Ibrahimi, Defect formation during dissimilar aluminium friction stir welded T-joints, Mechanics \& Industry 21, 205 (2020) 